Article

\title{
Diverse Responses of Remotely Sensed Grassland Phenology to Interannual Climate Variability over Frozen Ground Regions in Mongolia
}

\section{Zhigang Sun ${ }^{1, \dagger}$, Qinxue Wang ${ }^{2, \dagger}, *$, Qingan Xiao ${ }^{2}$, Ochirbat Batkhishig ${ }^{3}$ and Masataka Watanabe ${ }^{4}$}

1 Key Laboratory of Ecosystem Network Observation and Modeling, Institute of Geographic Sciences and Natural Resources Research, Chinese Academy of Sciences, Beijing 100101, China; E-Mail: sun.zhigang@igsnrr.ac.cn

2 Center for Regional Environmental Research, National Institute for Environmental Studies, Tsukuba 305-8506, Japan; E-Mail: xiao.qingan@nies.go.jp

3 Institute of Geography, Mongolian Academy of Sciences, Ulaanbaatar 14192, Mongolia; E-Mail: batkhishig@gmail.com

4 Research and Development Initiative, Chuo University, Tokyo 192-0393, Japan; E-mail: masawata@tamacc.chuo-u.ac.jp

$\dagger$ These authors contributed equally to this work.

* Author to whom correspondence should be addressed; E-Mail: wangqx@nies.go.jp; Tel.: +81-29-850-2128; Fax: +81-29-850-2128.

Academic Editors: Alfredo R. Huete and Prasad S. Thenkabail

Received: 2 November 2014 / Accepted: 25 December 2014 / Published: 31 December 2014

\begin{abstract}
Frozen ground may regulate the phenological shifts of dry and cold grasslands at the southern edge of the Eurasian cryosphere. In this study, an investigation based on the MODIS Collection 5 phenology product and climatic data collected from 2001 to 2009 reveals the diverse responses of grassland phenology to interannual climate variability over various frozen ground regions in Mongolia. Compared with middle and southern typical steppe and desert steppe, the spring (start of season; SOS) and autumn (end of season; EOS) phenological events of northern forest steppe with lower air temperature tend to be earlier and later, respectively. Both the SOS and EOS are less sensitive to climate variability in permafrost regions than in other regions, whereas the SOS of typical steppe is more sensitive to both air temperature and precipitation over sporadic permafrost and seasonal frozen
\end{abstract}


ground regions. Over various frozen ground regions in Mongolia; the SOS is mainly dominated by the prior autumn precipitation, and frozen ground plays a vital role in storing the precipitation of the previous autumn for the subsequent grass green-up. The EOS is mainly dominated by autumn air temperature. These findings could help to improve phenological models of grasslands in extremely dry and cold regions.

Keywords: air temperature; precipitation; spring phenology; autumn phenology; grassland; frozen ground; permafrost

\section{Introduction}

Vegetation phenology has been of increasing interest because it is sensitive to climate warming [1-3]. Long term in situ records and satellite remote sensing observations have revealed that spring and autumn events of temperate vegetation over the Northern Hemisphere have advanced and been delayed by a couple of days because of global warming, respectively, depending on the locations and datasets used $[4,5]$. Phenology shifts will in turn affect the climate through biogeochemical and biophysical effects [6]. In view of the socioeconomic aspect, phenology shifts will also affect the agricultural system [7]. For example, shifts in the onset of grass green-up in spring in Mongolia force herders to reschedule the traditional movement of their livestock just after the cold and forage-short winter months.

Most observed phenology trends are attributed to air temperature [4,8-11]. Theoretically, vegetation phenology is controlled by many factors that differ with climate [2]. In humid regions, it is mainly controlled by the degree of winter chilling, photoperiod, and temperature [2,10,11]. In arid regions, it is mainly controlled by air temperature and precipitation (or soil moisture) [12-18].

Mongolia is located at the southern edge of the Eurasian cryosphere, overlying various frozen ground types. Mongolia has a dry and cold climate, and climate warming is obvious, with a $1.8^{\circ} \mathrm{C}$ increase in air temperature over the last 60 years [19]. Such an area is perfect for understanding the response of vegetation phenology to climate change under extremely dry and cold climatic conditions. Previous studies show that spring phenology of grasslands is mainly controlled by spring precipitation in arid regions on the Tibetan Plateau and in the north of China $[9,15,16,18,20]$. These study areas are mainly located in seasonal frozen ground regions. The role of frozen ground in regulating spring phenology of dry and cold grasslands has not been reported previously. Throughout this study, therefore, both the start of season (SOS) and end of season (EOS) of the grass growing season are investigated over various frozen ground regions in Mongolia, and four questions are addressed.

(1) What is the response of grassland phenology to interannual climate variability? Three grassland types (forest steppe, typical steppe, and desert steppe) cover most of Mongolia; their spatial distribution is determined by annual precipitation. Three types of frozen ground (permafrost, sporadic permafrost, and seasonal frozen ground) underlie Mongolia; their spatial distribution is determined by annual mean air temperature. The overlap of grasslands and underlying frozen ground generates diverse landscapes in Mongolia. Therefore, the grassland phenology is expected to display diverse responses to interannual climate variability. 
(2) Does air temperature or precipitation dominate SOS and EOS, or do temperature and precipitation have equal impact? Air temperature before SOS usually triggers vegetation to leaf out if there is no water deficit [2]. However, soil water content is a key limiting factor for this event in arid areas [12,16,18], which mainly originates from precipitation over dry grasslands. Then, precipitation may become a trigger for drier environments. Shen et al. [20] suggested that precipitation exerts a strong influence on green-up onset of dry grasslands on the Qinghai-Tibetan Plateau. Because of a similar vegetation-climate pattern, such an influence might also occur in Mongolia with its drier and colder climate. Previous studies found that EOS is mainly controlled by air temperature [4,5]. The climatic factors regulating SOS and EOS are further investigated in Mongolia.

(3) During which period is precipitation accumulated for triggering grassland green-up if precipitation dominates SOS? There is no consensus on this question in the scientific community. White et al. [12] summed precipitation starting on the first day of the year in the United States. Li and Zhou [21] considered the previous year's precipitation with a weighted coefficient in Northeast China. Shen et al. [20] tested the functional period from 5 to 90 days before SOS on the Qinghai-Tibetan Plateau and found it to be mainly within a month before SOS. This study considered precipitation that fell from spring backward to the previous autumn.

(4) What role does frozen ground play in the effect of precipitation on SOS? The frost and thaw processes of frozen ground from late autumn to the following spring affect the concurrent water cycle [22], suggesting that frozen ground may closely relate to the spring phenology of grasslands in Mongolia.

Because of a lack of long-term phenological records of grasslands over large areas in Mongolia, the above questions continue to confuse the scientific community and stakeholders. The global yearly 500-m Moderate-Resolution Imaging Spectroradiometer (MODIS) Collection 5 vegetation phenology product and ground-based data allow us to answer the above four questions.

In summary, this study aims to provide a detailed and quantified investigation on the response of grassland phenology to interannual climate variability, and to quantify the role of frozen ground in regulating grassland phenology in various frozen ground regions in Mongolia.

\section{Materials and Methods}

\subsection{Study Area and Sites Used}

Livestock, a key segment of Mongolia's economy, entirely depends on grasslands, which account for approximately $80 \%$ of the total land area (yellow regions shown in Figure 1). Mongolia has a dry and cold climate. As shown in Table 1, the annual mean air temperature (ANN-Ta) ranges from approximately $-7-6{ }^{\circ} \mathrm{C}$, and the annual total precipitation (ANN-P) ranges from approximately 100 to $300 \mathrm{~mm}$. Such a climate only allows local and hardy grasslands (desert steppe, steppe, and forest steppe) to exist.

Twenty-four national meteorological stations across Mongolia have kept complete air temperature and precipitation records for the last decade (Figure 1). These stations are located in areas of three grassland types: forest steppe in the northern regions (seven stations shown in Figure 1 and Table 1), desert steppe along the boundary of the desert in the southern and western regions (ten stations), and typical steppe lying between the forest steppe and the desert steppe (seven stations). This spatial 
distribution of grasslands is determined by ANN-P. The forest steppe has ANN-P $>270 \mathrm{~mm}$, the steppe has ANN-P from 180 to $270 \mathrm{~mm}$, and the desert steppe has ANN-P $<180 \mathrm{~mm}$. The 24 meteorological stations also represent three types of frozen ground: permafrost with an ANN-Ta limit of less than $-1{ }^{\circ} \mathrm{C}$ (seven stations shown in Table 1), sporadic permafrost with an ANN-Ta limit of $0 \pm 1{ }^{\circ} \mathrm{C}$ (eleven stations), and seasonal frozen ground with an ANN-Ta limit of greater than $1{ }^{\circ} \mathrm{C}$ (six stations). This frozen ground classification is equivalent to that based on a surface frost index [19]. The surface frost index is a climate-based index calculated using the sums of negative and positive temperatures over a single year [23]. Meteorological stations over three grassland types overlaying three frozen ground types could provide diverse climatic and phenological data across Mongolia.

Table 1. Description of meteorological stations, including ID, name, geolocation (Lat.: latitude; Lon.: longitude; Ele.: elevation), annual mean air temperature (ANN-Ta), annual total precipitation (ANN-P) with standard deviations calculated during the period of 2000-2009, and grassland/frozen ground types (FS: forest steppe; ST: steppe; DS: desert steppe; 0P: seasonal frozen ground; 1P: sporadic permafrost; $2 \mathrm{P}$ : permafrost).

\begin{tabular}{|c|c|c|c|c|c|c|c|}
\hline $\begin{array}{c}\text { Grassland/ } \\
\text { Frozen } \\
\text { Ground Type }\end{array}$ & $\begin{array}{c}\text { Station } \\
\text { ID }\end{array}$ & $\begin{array}{c}\text { Station } \\
\text { Name }\end{array}$ & Lat. $\left({ }^{\circ}\right)$ & Lon. $\left({ }^{\circ}\right)$ & Ele. (m) & $\begin{array}{c}\text { ANN-Ta } \\
\left({ }^{\circ} \mathrm{C}\right)\end{array}$ & $\begin{array}{c}\text { ANN-P } \\
\text { (mm/year) }\end{array}$ \\
\hline $\mathrm{FS} / 2 \mathrm{P}$ & 442030 & Rinchinlhumbe & 51.117 & 99.667 & 1583 & $-6.2 \pm 0.8$ & $273.8 \pm 62.1$ \\
\hline $\mathrm{FS} / 2 \mathrm{P}$ & 442070 & Hatgal & 50.433 & 100.150 & 1668 & $-3.6 \pm 0.8$ & $281.1 \pm 80.3$ \\
\hline $\mathrm{FS} / 1 \mathrm{P}$ & 442300 & Tarialan & 49.567 & 102.000 & 1235 & $0.5 \pm 0.7$ & $306.6 \pm 65.7$ \\
\hline $\mathrm{FS} / 1 \mathrm{P}$ & 442320 & Hutag & 49.383 & 102.700 & 938 & $0.3 \pm 0.9$ & $295.7 \pm 54.8$ \\
\hline $\mathrm{FS} / 1 \mathrm{P}$ & 442390 & Bulgan & 48.800 & 103.550 & 1208 & $-0.1 \pm 0.7$ & $270.1 \pm 43.8$ \\
\hline $\mathrm{FS} / 1 \mathrm{P}$ & 442410 & Baruunharaa & 48.917 & 106.067 & 807 & $0.4 \pm 0.9$ & $284.7 \pm 91.3$ \\
\hline $\mathrm{FS} / 0 \mathrm{P}$ & 442820 & Tsetserleg & 47.450 & 101.467 & 1691 & $1.7 \pm 0.7$ & $310.3 \pm 54.8$ \\
\hline $\mathrm{ST} / 2 \mathrm{P}$ & 442130 & Baruunturuun & 49.650 & 94.400 & 1232 & $-2.3 \pm 1.0$ & $211.7 \pm 25.6$ \\
\hline $\mathrm{ST} / 2 \mathrm{P}$ & 442250 & Tosontsengel & 48.733 & 98.200 & 1723 & $-5.0 \pm 0.9$ & $222.7 \pm 84.0$ \\
\hline $\mathrm{ST} / 1 \mathrm{P}$ & 442920 & Ulaanbaatar & 47.917 & 106.867 & 1306 & $-0.7 \pm 0.7$ & $251.9 \pm 62.1$ \\
\hline $\mathrm{ST} / 1 \mathrm{P}$ & 443020 & Bayan-ovoo & 47.783 & 112.117 & 926 & $0.9 \pm 0.9$ & $200.8 \pm 40.2$ \\
\hline $\mathrm{ST} / 1 \mathrm{P}$ & 443040 & Underkhaan & 47.317 & 110.633 & 1033 & $0.4 \pm 0.9$ & $219.0 \pm 62.1$ \\
\hline $\mathrm{ST} / 1 \mathrm{P}$ & 443130 & Khalkh-gol & 47.617 & 118.617 & 688 & $0.4 \pm 0.8$ & $270.1 \pm 47.5$ \\
\hline $\mathrm{ST} / 0 \mathrm{P}$ & 443140 & Matad & 47.167 & 115.633 & 907 & $2.1 \pm 0.8$ & $193.5 \pm 76.7$ \\
\hline $\mathrm{DS} / 2 \mathrm{P}$ & 442120 & Ulaangom & 49.800 & 92.083 & 939 & $-1.9 \pm 1.0$ & $135.1 \pm 40.1$ \\
\hline $\mathrm{DS} / 2 \mathrm{P}$ & 442750 & Bayanbulag & 46.833 & 98.083 & 2255 & $-3.1 \pm 0.9$ & $127.8 \pm 58.4$ \\
\hline $\mathrm{DS} / 2 \mathrm{P}$ & 442840 & Galuut & 46.700 & 100.133 & 2126 & $-3.3 \pm 1.1$ & $142.4 \pm 32.9$ \\
\hline $\mathrm{DS} / 1 \mathrm{P}$ & 442150 & Omno-gobi & 49.017 & 91.717 & 1590 & $-0.3 \pm 1.1$ & $131.4 \pm 51.1$ \\
\hline $\mathrm{DS} / 1 \mathrm{P}$ & 442770 & Altai & 46.400 & 96.250 & 2181 & $-0.4 \pm 0.8$ & $157.0 \pm 51.1$ \\
\hline $\mathrm{DS} / 1 \mathrm{P}$ & 442870 & Bayanhongor & 46.133 & 100.683 & 1859 & $0.9 \pm 0.7$ & $175.2 \pm 73.0$ \\
\hline $\mathrm{DS} / 0 \mathrm{P}$ & 442980 & Choir & 46.450 & 108.217 & 1286 & $1.9 \pm 0.8$ & $153.3 \pm 87.6$ \\
\hline $\mathrm{DS} / 0 \mathrm{P}$ & 443360 & Saikhan-ovoo & 45.450 & 103.900 & 1316 & $3.3 \pm 0.8$ & $113.2 \pm 51.1$ \\
\hline $\mathrm{DS} / 0 \mathrm{P}$ & 443520 & Bayandelger & 45.733 & 112.367 & 1101 & $3.0 \pm 0.8$ & $160.6 \pm 69.4$ \\
\hline $\mathrm{DS} / 0 \mathrm{P}$ & 443580 & Zamyn-uud & 43.733 & 111.900 & 964 & $5.1 \pm 0.7$ & $135.1 \pm 29.2$ \\
\hline
\end{tabular}




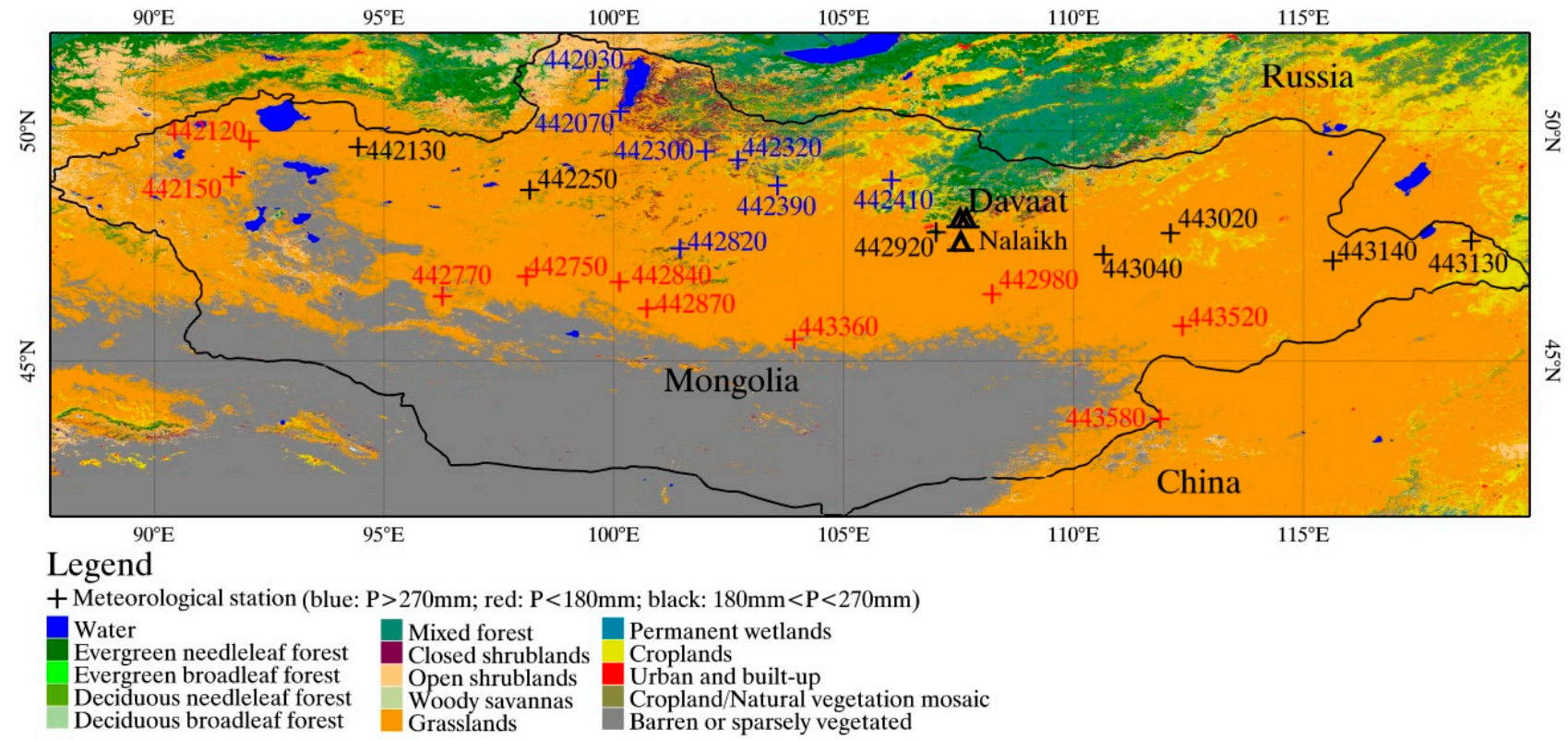

Figure 1. Land covers, meteorological stations, and three experiment sites used in this study.

Three automatic weather stations (AWS) are located at Nalaikh and Davaat, near Ulaanbaatar (Figure 1). The Nalaikh experiment site (typical steppe) and two Davaat experiment sites (typical steppe and forest steppe) are a part of the observation network for the early detection of global warming impact sponsored by the Ministry of Environment, Japan [24]. The AWS stations record air temperature, humidity, wind speed, wind direction, rainfall, ground surface temperature, soil temperature, soil water content, and four components of radiation fluxes. Recordings are taken at 30 min intervals.

\subsection{Data Used}

This study used remote sensing data, climatic data, and AWS observational data. Climatic data and AWS observational data were used to investigate the factors driving phenology shifts.

Climatic data from meteorological stations: Daily air temperature and precipitation data collected from 2000 to 2009 from 24 meteorological stations in Mongolia were downloaded from the National Climatic Data Center of the National Oceanic and Atmospheric Administration (NCDC-NOAA, USA; http://www.ncdc.noaa.gov/).

Observational data from three experiment sites: Soil water content at a depth of $5 \mathrm{~cm}$, precipitation, and air temperature data collected at 30 min intervals from 2007 to 2012 were used.

Remotely sensed phenology data: The MODIS Collection 5 phenology product between 2001 and 2009, with a tile range of h23-h26 and v03-v04, were downloaded from the Reverb of NASA's Earth Observing System (http://earthdata.nasa.gov/). The algorithm for estimating phenology is based on a piecewise logistic model fitting 8-day $500 \mathrm{~m}$ enhanced vegetation index (EVI) time series [25,26]. The MCD12Q2 product has four layers related to phenology: onset of greenness increase (beginning of EVI increase), onset of greenness maximum (reaching the maximum EVI), onset of greenness decrease (beginning of EVI decrease), and onset of greenness minimum (reaching the minimum EVI). In this study, the layers of onset of greenness increase (i.e., SOS) and onset of greenness minimum (i.e., EOS) are used for investigation. 
Remotely sensed EVI data: The 2007-2012 MOD13Q1 (Terra) and MYD13Q1 (Aqua) 16-day $250 \mathrm{~m}$ EVI data that correspond to the geographic locations of the three experiment sites were downloaded from the Reverb of NASA's Earth Observing System (http://earthdata.nasa.gov/). The 16-day Terra/MODIS and Aqua/MODIS EVI time series overlap by 8 days, resulting in new composite EVI time series every 8 days. This new EVI time series is used to describe the growing patterns of grasslands in this study.

\subsection{Analytical Methods}

Mean seasonal air temperature and precipitation from 2000 to 2009 were calculated for spring (March-May, MAM), summer (June-August, JJA), autumn (September-November, SON), and winter (December-February, DJF). The SOS and EOS time series from 2001 to 2009 were extracted from the MODIS phenology image stack according to the locations of the 24 meteorological stations. Existing knowledge suggests that spring and autumn phenological events of vegetation strongly relate to air temperature and precipitation in spring and autumn in arid regions, respectively $[4,9,12,14-16,20]$. To consider the effect of water stored in frozen soil and snow melt on SOS, winter mean precipitation (DJF-P, $\mathrm{mm} /$ day) and mean precipitation of the previous autumn (Pre-SON-P, mm/day) were included in the analysis along with spring mean air temperature (MAM-Ta, ${ }^{\circ} \mathrm{C}$ ) and spring mean precipitation (MAM-P, $\mathrm{mm}$ /day). To consider the potential effect of grassland robustness on EOS, summer mean precipitation (JJA-P, mm/day) was included in the analysis along with autumn mean air temperature $\left(\mathrm{SON}-\mathrm{Ta},{ }^{\circ} \mathrm{C}\right.$ ) and autumn mean precipitation (SON-P, mm/day). The above climatic factors could be helpful for understanding the SOS and EOS responses of grasslands to interannual climate variability over various frozen ground regions across Mongolia.

The partial least squares (PLS) regression was used to investigate the relationships between independent climate factors and dependent SOS and EOS, respectively. The PLS method is particularly suited when there is multicollinearity among independent variables. The climatic factors (e.g., air temperature and precipitation) controlling vegetation phenology may correlate each other; therefore, the PLS method could be useful to understand the response of vegetation phenology to climate change [9]. The variable importance in the projection (VIP) from the PLS analysis can compactly summarize the importance of considered climatic variables for SOS and EOS changes. As suggested by Eriksson et al. [27] and Yu et al. [9], the independent variables with VIP scores above 0.8 are identified as important ones for the model. In this study, both the Pearson correlation coefficient $(R)$ and VIP can measure the strength of the relationships between considered climatic factors and grassland phenology. Meanwhile, the $R$ can indicate the direction of the relationship, whether positive or negative. Both $R$ and VIP are calculated by using the Addinsoft XLSTAT tool.

All PLS analyses were based on 2000-2009 ground data (independent variables) from the 24 meteorological stations and 2001-2009 MODIS phenology data (dependent variables) corresponding to the geographic locations of the 24 meteorological stations. According to the grassland type and frozen ground type (see Table 1), firstly, all data were divided into three groups according to the type of grasslands (forest steppe, steppe, and desert steppe); secondly, each group was further divided into three sub-groups according to the type of frozen ground (permafrost, sporadic permafrost and seasonal frozen ground); finally, PLS analyses were conducted for three groups and then for nine sub-groups. The ANOVA test was used to assess whether SOS and EOS dates differ among grassland types and permafrost types. 


\section{Results}

\subsection{MODIS SOS and EOS of Grasslands with a Dry and Cold Climate across Mongolia}

The SOS and EOS from the MODIS phenology images are consistent with the phenological dates reported by Batima (2006) and Shinoda et al. [14]. Across Mongolia, the SOS of grasslands ranges from early April to late May, and the EOS of grasslands ranges from early September to middle October (Figure 2). The MODIS-based growing season duration of grasslands from later spring to early autumn well matches local climatic conditions. This suggests that the MODIS phenology product is reasonable for a dry and cold grassland landscape. However, the SOS and EOS are diverse for three grassland types (Figure 2).

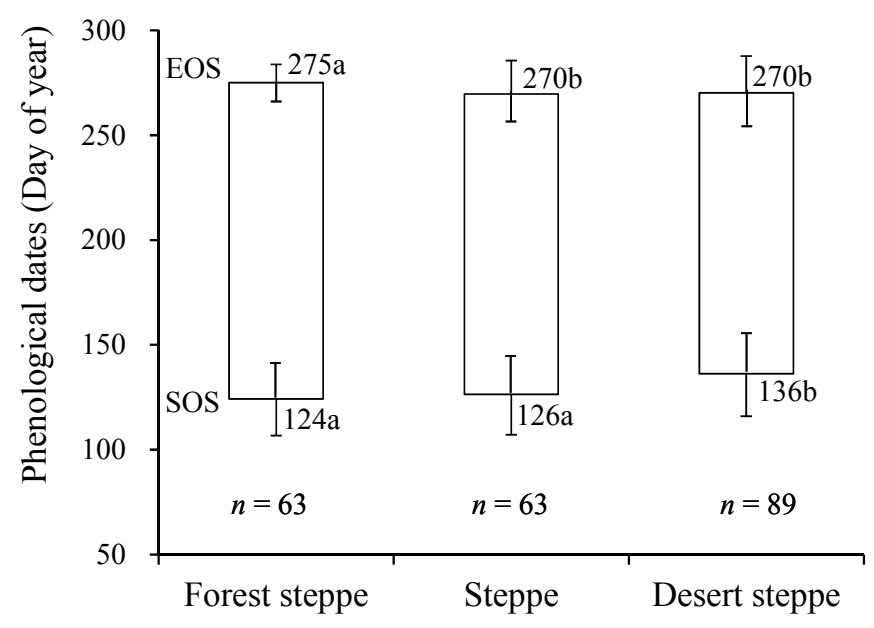

Figure 2. Means and standard deviations of SOS and EOS for three steppe types in Mongolia. The $n$ is the number of phenological records for SOS and EOS. The bar is the standard deviation. The same letters following mean values indicate no significant difference in SOS and EOS between three grassland types at the 5\% significance level, respectively.

\subsubsection{SOS of Grasslands over Various Frozen Ground Regions}

Although the forest steppe and typical steppe have a colder climate, the SOS of the forest steppe and typical steppe is earlier than that for the desert steppe by approximately 10 days (Figure 2). The SOS of the forest steppe has less standard deviation (17 for the forest steppe; 19 and 20 for the steppe and the desert steppe, respectively). This means that the SOS of the forest steppe has less interannual variability than the steppe and desert steppe. Further investigations were conducted for each grassland type with three frozen ground types (Figure 3). There is almost no difference in the forest steppe SOS over the three frozen ground types, but the SOS over permafrost has less interannual variability (standard deviation of 12 for permafrost, 20 for sporadic permafrost, and 16 for seasonal frozen ground). As shown in Figure 3, the SOS over the three frozen ground types is diverse for both the steppe and the desert steppe. For the steppe, the SOS over permafrost regions is obviously earlier than that over other regions by approximately half a month and has less interannual variability (standard deviation of 12 for permafrost, 20 for sporadic permafrost, and 22 for seasonal frozen ground). For the desert steppe, the SOS over sporadic permafrost regions is $2-3$ weeks earlier than that over other regions. The delayed SOS of the desert steppe over permafrost regions may be caused by a severer climate. As shown in Table 1 
and Figure 1, the annual mean air temperature is lower than $-2{ }^{\circ} \mathrm{C}$, and the annual total precipitation is less than $150 \mathrm{~mm}$ at the Ulaangom, Bayanbulag, and Galuut stations in the western regions.

As shown in Figures 2 and 3, the findings indicate that the SOS of the forest steppe tends to be earlier than that of other two steppe types, and the interannual climate variability has less impact on the SOS of the forest steppe, especially in permafrost regions. This suggests that underneath frozen ground, stored water might moderate the impact of climate variability on grassland SOS across Mongolia.

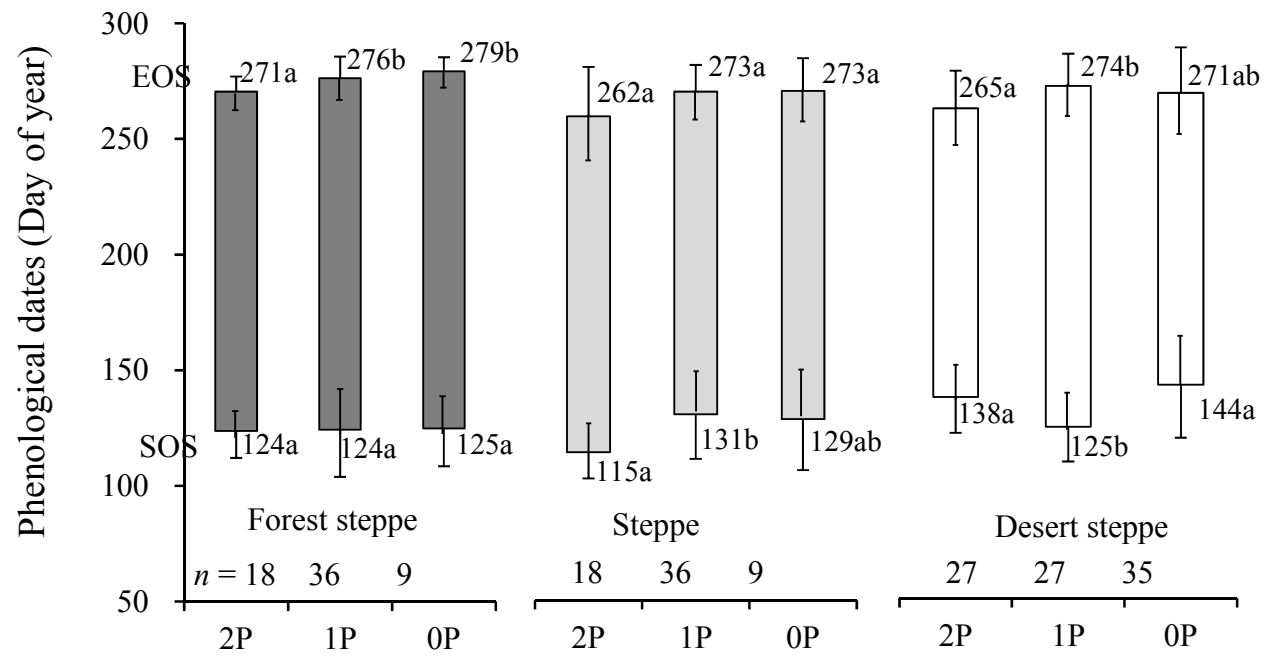

Figure 3. Means and standard deviations of SOS and EOS for three steppe types with three frozen ground types in Mongolia. The $n$ is the number of phenological records for SOS and EOS. The $0 \mathrm{P}, 1 \mathrm{P}$, and $2 \mathrm{P}$ represent seasonal frozen ground, sporadic permafrost, and permafrost, respectively. The bar is the standard deviation. For each grassland type, the same letters following mean values indicate no significant difference in SOS and EOS between three permafrost types at the $5 \%$ significance level, respectively.

\subsubsection{EOS of Grasslands over Various Frozen Ground Regions}

There is no obvious difference in the EOS of the three steppe types (Figure 2). The EOS of the steppe and the desert steppe is earlier than that of the forest steppe only by 5 days, but the EOS of the forest steppe has less interannual variability (standard deviation of 9 for the forest steppe; 16 and 18 for the steppe and the desert steppe, respectively). Further investigations were conducted on the EOS of each grassland type with three frozen ground types (Figure 3). The EOS of all three steppe types over permafrost regions tends to be earlier than that over other regions by about a week. Compared with the steppe and the desert steppe over the three frozen ground types, the forest steppe EOS has less interannual variability (standard deviation of 7 for permafrost, 9 for sporadic permafrost, and 6 for seasonal frozen ground, respectively).

As shown in Figures 2 and 3, the findings suggest that the EOS of the forest steppe tends to be a little bit late and has less sensitivity to interannual climate variability. The EOS of each steppe type over permafrost regions tends to be earlier because of relatively low air temperatures in autumn. 


\subsection{Driving Factors of Interannual Changes in SOS and EOS in Mongolia}

The $R$ and VIP score were calculated to measure the relationship between grassland phenology and considered climatic factors for the three steppe types and further for the three underlying frozen ground types. Below are detailed results for SOS and EOS, respectively.

\subsubsection{Driving Factors of Interannual Changes in SOS}

Although the correlations between SOS and climatic factors and VIP scores for climatic factors vary with the grassland type, significant negative correlations between SOS and precipitation and larger VIP scores for precipitation factors exist across all three grassland types. As shown in Figure 4a, SOS has a significant negative correlation with Pre-SON-P for the forest steppe $(p<0.05)$ and the steppe $(p<0.01)$, whereas SOS has a significant negative correlation with both MAM-P $(p<0.01)$ and Pre-SON-P $(p<0.01)$ for the desert steppe. It is noted that the SOS of the steppe has a significant positive correlation with MAM-Ta. This indicates that the SOS of the steppe could be delayed when rapid increase in air temperature causes rapid increase in evaporation and thus sharp decrease in soil moisture in spring. This case is not significant for the forest steppe because of less soil moisture stress and for the desert steppe because of existing strong soil moisture stress. The VIP scores for climatic factors indicate the importance of climatic factors to SOS. The findings from Figure $4 \mathrm{~b}$ are consistent with those from Figure $4 \mathrm{a}$. The VIP score of DJF-P for the forest steppe is also greater than 0.8 (Figure $4 \mathrm{~b}$ ). This indicates that winter precipitation has some influence on the SOS of the forest steppe, but its influence is not significant (Figure 4a). The above findings indicate that the SOS of all three grassland types tends to be dominated by previous autumn precipitation across Mongolia, and spring precipitation is also vital for the spring green-up of the desert steppe.
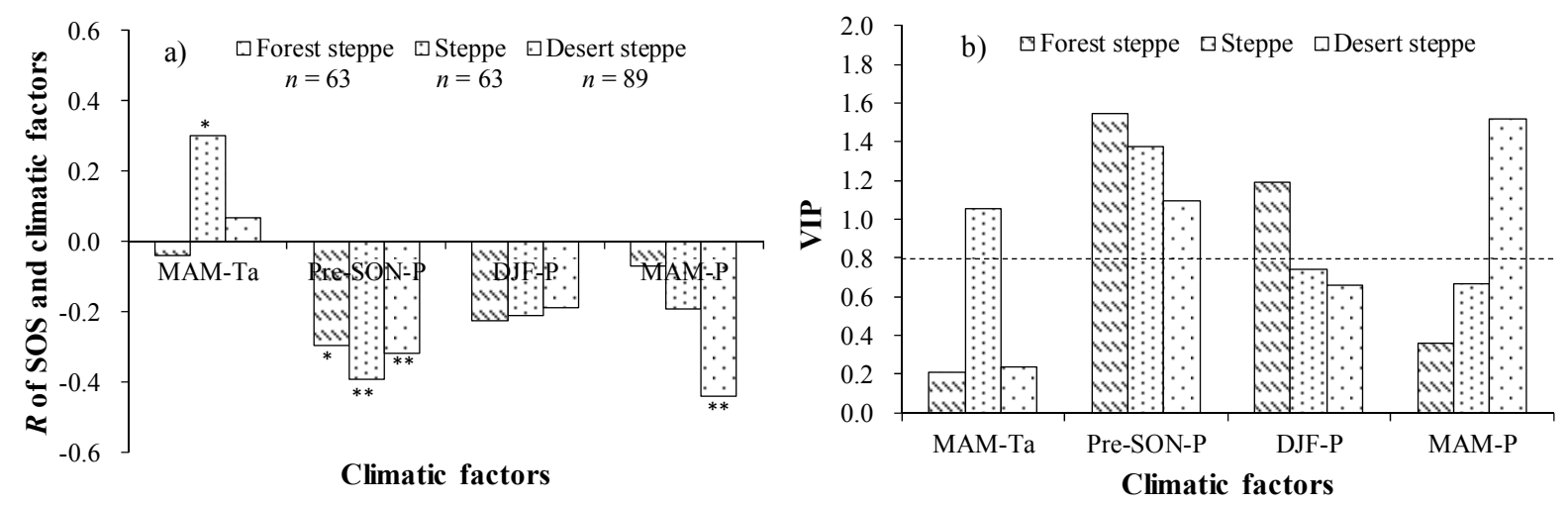

Figure 4. Correlation (a) between SOS and climatic factors for three grassland types and VIP (b) for considered variables. * indicates the significance level of 0.05 and ** indicates the significance level of 0.01 . The $n$ is the number of phenological records for SOS.

Dominant factors driving interannual changes in grassland SOS are diverse among three frozen ground types. Figure 5 depicts the correlations between SOS and climatic factors and shows VIP scores for climatic factors for each grassland type with the three frozen ground types (where the VIP value coincides with the strength of correlation). The forest steppe SOS has a significant negative correlation with DJF-P $(p<0.05)$ over permafrost regions and with Pre-SON-P $(p<0.05)$ over sporadic permafrost 
regions. The steppe SOS has a significant negative correlation with MAM-Ta $(p<0.01)$ over permafrost regions and with Pre-SON-P $(p<0.01)$ over sporadic permafrost regions. The desert steppe SOS has a significant negative correlation with Pre-SON-P $(p<0.05)$ and DJF-P $(p<0.01)$ over permafrost regions, with Pre-SON-P $(p<0.01)$ over sporadic permafrost regions, and with Pre-SON-P $(p<0.05)$ and MAM-P $(p<0.01)$ over seasonal frozen ground regions. Through the $R$ and VIP values, results shown in Figure $5 \mathrm{a}-\mathrm{c}$ and suggest that the SOS of the three steppe types is dominated by previous autumn precipitation over sporadic permafrost regions. For permafrost regions, the SOS of the forest steppe is dominated by winter precipitation, the SOS of the steppe is dominated by spring air temperature, and the SOS of the desert steppe is dominated by winter and previous autumn precipitation. For seasonal frozen ground regions, the SOS of the desert steppe is dominated by the precipitation of spring and the previous autumn.
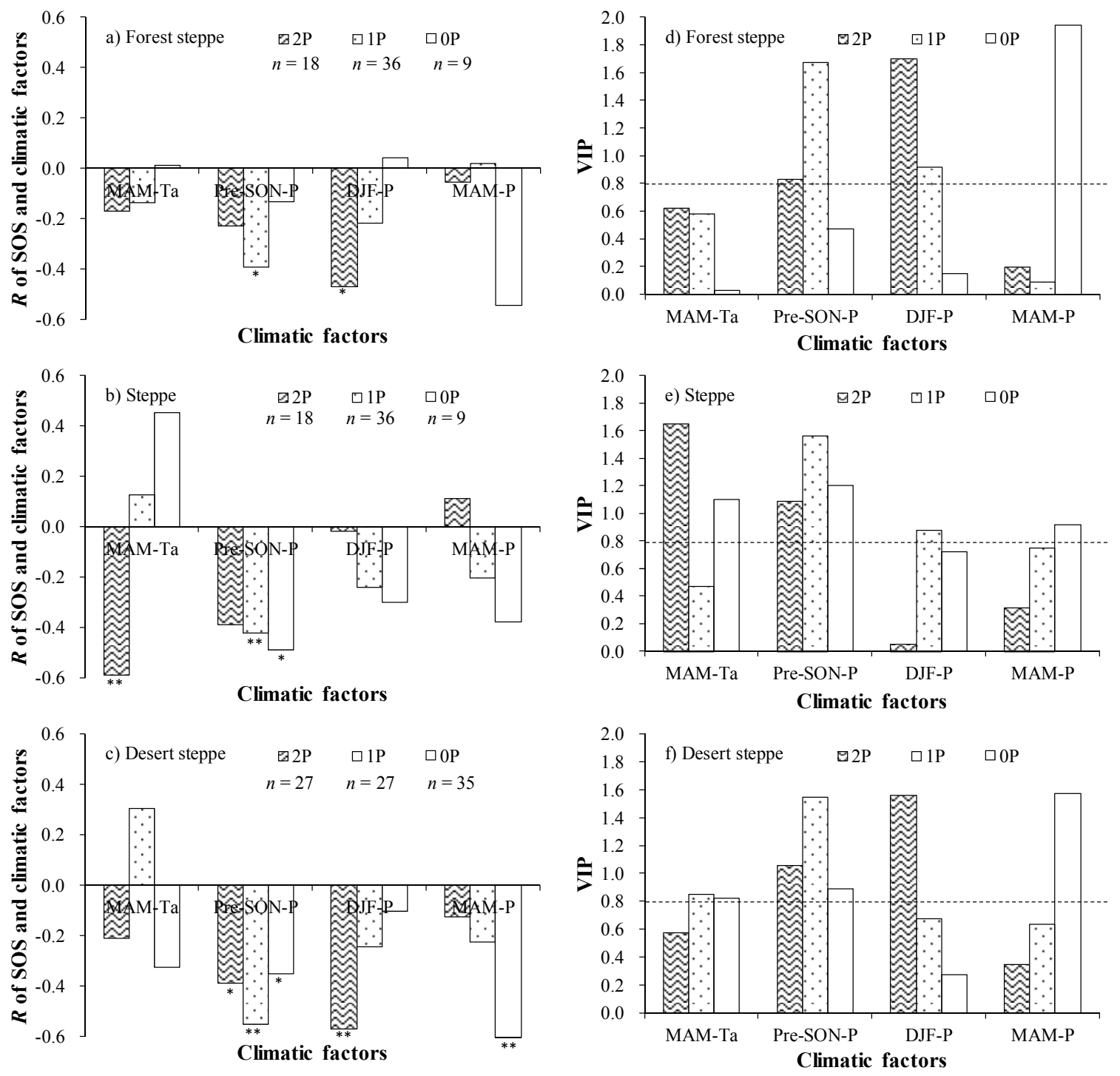

Figure 5. Correlation $(\mathbf{a}-\mathbf{c})$ between SOS and climatic factors for the three grassland types with three frozen ground types and VIP $(\mathbf{d}-\mathbf{f})$ for considered variables. * indicates the significance level of 0.05 and ** indicates the significance level of 0.01 . The $n$ is the number of phenological records for SOS. The $0 \mathrm{P}, 1 \mathrm{P}$, and $2 \mathrm{P}$ represent seasonal frozen ground, sporadic permafrost, and permafrost, respectively. 


\subsubsection{Driving Factors of Interannual Changes in EOS}

Figure 6a,b shows that SON-Ta dominates EOS for the three grassland types (VIP $>0.8$ ), but the EOS significantly correlates with SON-Ta only for the forest steppe $(p<0.01)$ and the steppe $(p<0.05)$. As for each steppe type over the three frozen ground types, the forest steppe EOS over sporadic permafrost regions has a significant positive correlation with SON-Ta $(p<0.05)$, and the steppe EOS over permafrost regions has a significant positive correlation with JJA-P $(p<0.05)$ (Figure $7 \mathrm{a}-\mathrm{c})$. The values of $R$ and VIP in Figures 6 and 7 indicate that the EOS is dominated by autumn air temperature rather than precipitation, but precipitation in summer and autumn may be helpful for grasslands to improve their robustness and thus to delay EOS.
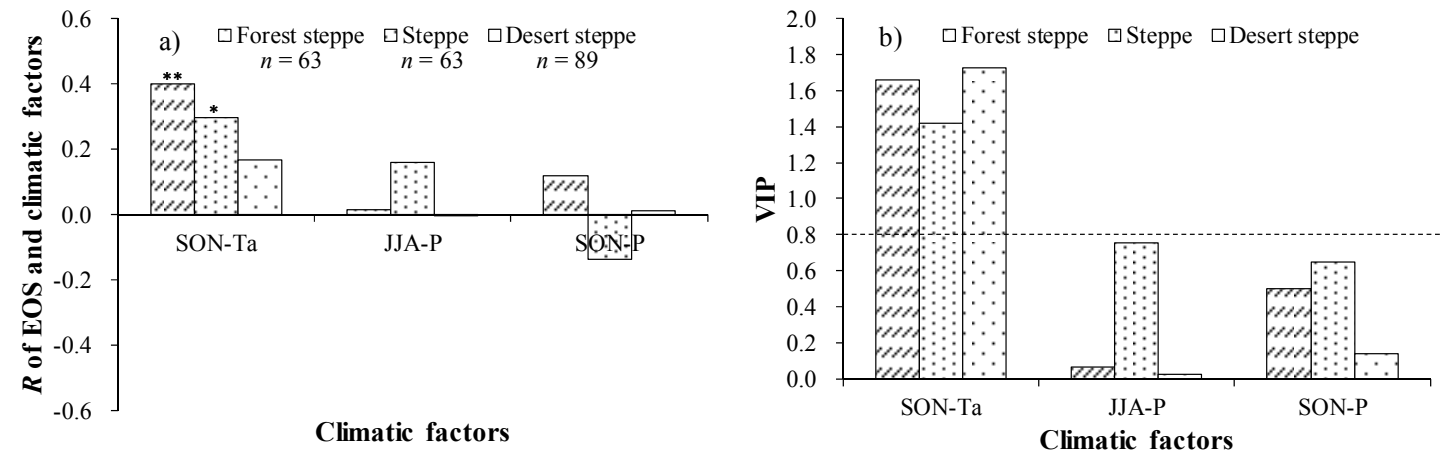

Figure 6. Correlation (a) between EOS and climatic factors for three grassland types and VIP (b) for considered variables. * indicates the significance level of 0.05 and ** indicates the significance level of 0.01 . The $n$ is the number of phenological records for EOS.
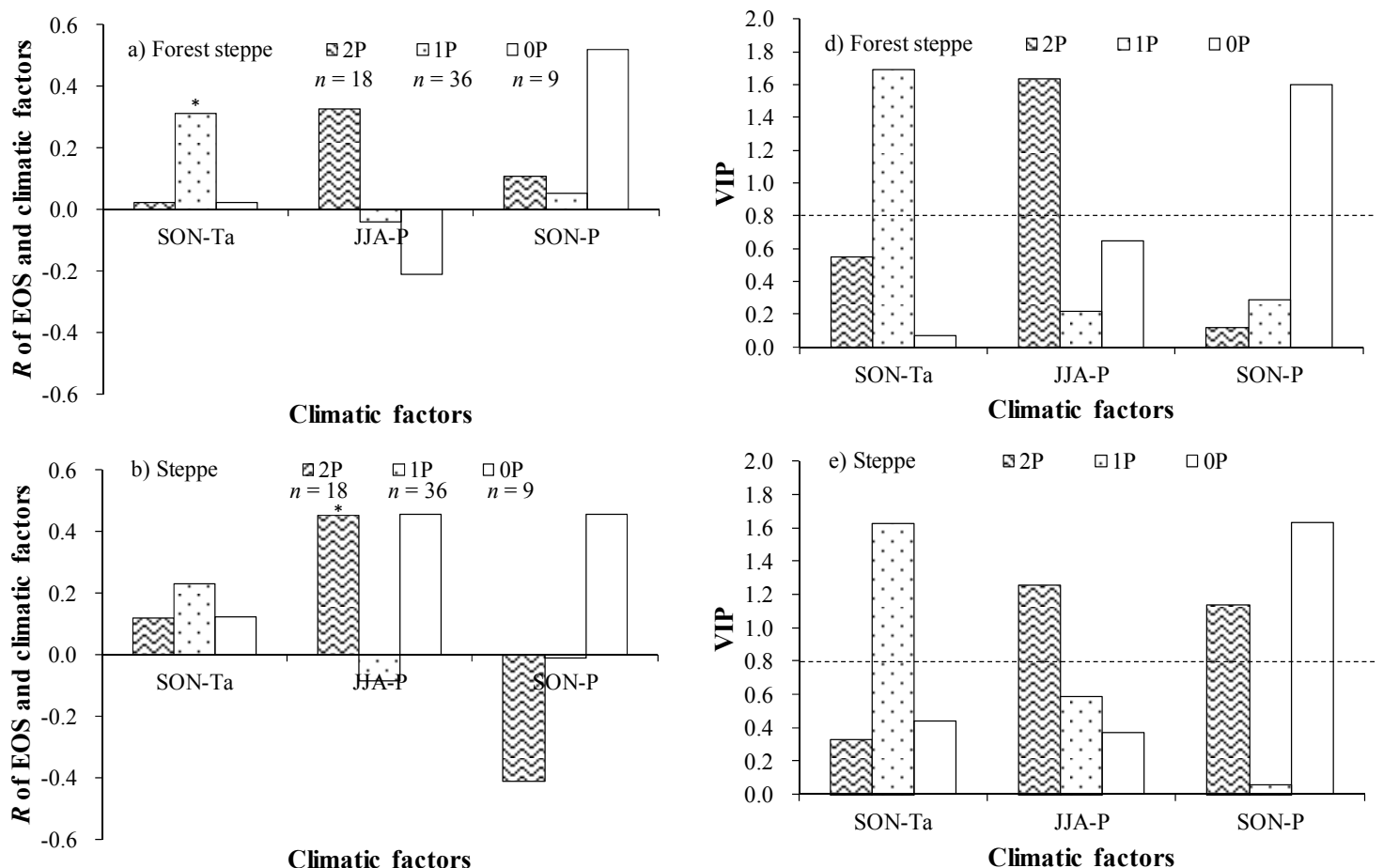

Figure 7. Cont. 

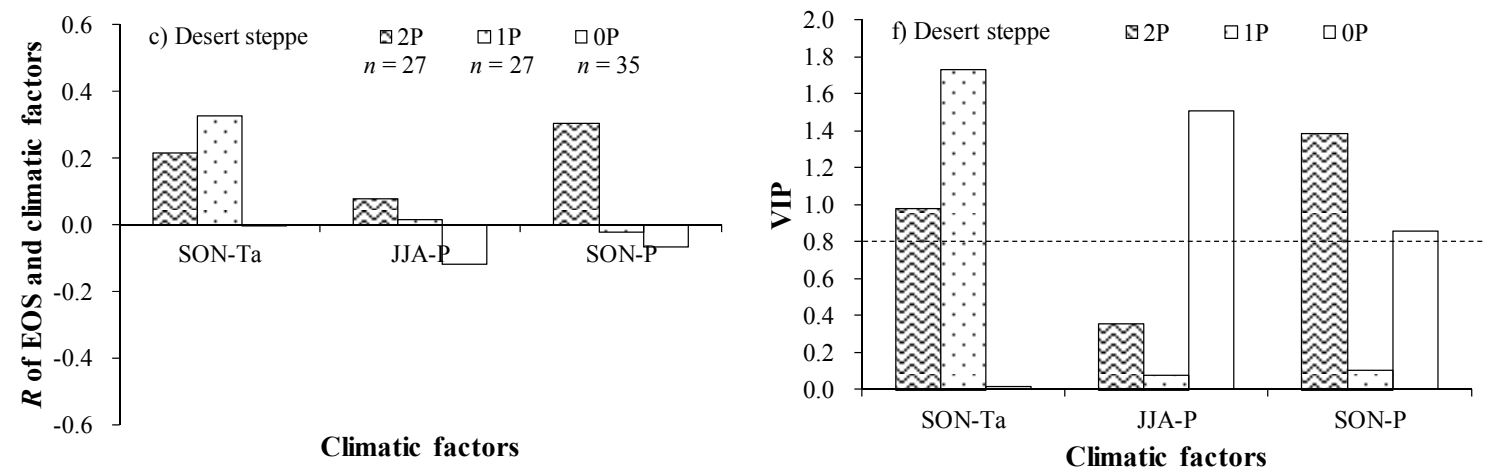

Figure 7. Correlation $(\mathbf{a}-\mathbf{c})$ between EOS and climatic factors for the three grassland types with three frozen ground types and VIP $(\mathbf{d}-\mathbf{f})$ for considered variables. * indicates the significance level of 0.05 and $* *$ indicates the significance level of 0.01 . The $n$ is the number of phenological records for EOS. The $0 \mathrm{P}, 1 \mathrm{P}$, and $2 \mathrm{P}$ represent seasonal frozen ground, sporadic permafrost, and permafrost, respectively.

\section{Discussions}

\subsection{Uncertainties in the MODIS Phenology Product for Grasslands and in the Use of Seasonal Means} of Climatic Factors

Remotely sensed land surface phenology (LSP) refers to the seasonal pattern of land surface vegetation within a given pixel [28]. This pixel could be a mixed or homogenous surface, depending on the heterogeneity of remotely sensed landscapes. Over relatively homogenous grasslands across Mongolia, the $500 \mathrm{~m}$ MODIS LSP captures the phenological development of local typical grasslands where several grass species could coexist. This study focused on grassland community rather than specific grass species; therefore, the MODIS LSP data could satisfy the investigation into the relationship of grassland phenology shifts and interannual climate variability in this study.

The MODIS phenology product has been validated for forestlands with one life cycle per year in North America [25,26] and double cropping lands in the North China Plain [29]. These studies suggested that the MODIS LSP product could reasonably detect the phenological development of forestlands and croplands, although there are a few uncertainties in detecting the phenological dates for the second crop in double cropping areas. The grasslands in Mongolia also have one life cycle per year. The accuracy of MODIS LSP for Mongolian grasslands could be comparable to that for forestlands in North America.

To explicitly predict spring phenology, the triggering thresholds of thermal accumulation, soil moisture, or other controlling factors need to be known. By means of long-term phenological data, these thresholds could be determined by averaging long term climatic data. For example, Shen et al. [20] and Liu et al. [18] determined the thresholds of cumulative temperature and precipitation using daily weather data before SOS over the span of 25 years in Inner Mongolia and on the Tibetan Plateau, respectively. Alternatively, empirical investigations of relationships between vegetation phenology and climatic factors could be undertaken by reviewing monthly or seasonal means of climatic factors. Such a strategy has been widely used by Cong et al. [15], Jeong et al. [4], Shen [11], Yu et al. [16], Yu et al. [10], and $\mathrm{Yu}$ et al. [9]. Instead of predicting phenological events, this study focuses on empirically investigating the diverse responses of grassland phenology to interannual climate variability and understanding the 
role of frozen ground in regulating vegetation phenology over various frozen ground regions across Mongolia. Therefore, seasonal means of climatic factors could be acceptable to answer the four questions proposed in this study.

\subsection{Dominant Climatic Factor Affecting SOS and EOS of Dry and Cold Grasslands}

Our analyses suggest that the SOS of Mongolian grasslands is dominated by precipitation, particularly by autumn precipitation of the previous year, whereas the EOS is dominated by autumn air temperature. Because of weak evapotranspiration in autumn [30], most precipitation in autumn is stored in frozen soil in winter and can be used for grass germination and development at the beginning of the next growing season. Frozen ground could be considered as a temporary reservoir of soil moisture during winter [31]. As shown in Figure 4, SOS correlates less with DJF-P than with Pre-SON-P. This means that precipitation in winter contributes less to grass growth in the following spring in Mongolia because it is remarkably lower than that in other seasons. The EOS of Mongolian grasslands is mainly controlled by air temperature. Grass usually ends its growth period when air temperature is close to $0^{\circ} \mathrm{C}$ in autumn in Mongolia.

A specific investigation with detailed in situ measurements at the Davaat steppe experiment site supports the above conclusions. Figure 8 shows the seasonal patterns of daily rainfall, mean air temperature, volumetric liquid soil water content at a depth of $5 \mathrm{~cm}$, and EVI at the Davaat site from 2007 to 2012. The SOS (i.e., green-up date) and EOS (i.e., green-end date) were determined by an EVI threshold of 0.15. The SOS and EOS dates match well with the observed patterns of soil water content and air temperature. Grass starts to grow when the cumulative $>0{ }^{\circ} \mathrm{C}$ air temperature is higher than approximately $30{ }^{\circ} \mathrm{C}$ and soil water content is greater than approximately $20 \%$ in spring, and ends its growth when air temperature is close to $0{ }^{\circ} \mathrm{C}$ in autumn. It is noted that the SOS in 2009 advanced by approximately two weeks because of plentiful precipitation $(51.2 \mathrm{~mm})$ in the autumn of 2008 . Observations shown in Figure 8 could confirm the driving factors for grassland SOS (precipitation) and EOS (air temperature) in Mongolia.

The findings in this study could help to counter recent tendencies to over-attribute spring phenological shifts to air temperature and could also help to improve phenological models of vegetation in an extremely dry and cold climate. Some recent studies reported that spring vegetation phenology is mainly controlled by air temperature in Northeast Asia and on the Tibetan Plateau within which some dry and cold regions exist, but precipitation was not well considered for these dry and cold regions in their studies [4,8-11]. As shown in Figures 4 and 5, our study shows that spring phenology of grasslands is mainly controlled by precipitation in Mongolia, particularly by the precipitation of the previous autumn. Most existing vegetation phenological models based on dominant driving factors and their thresholds ignore the contribution of the precipitation of the previous autumn and the role of frozen ground in dry and cold regions $[12,18,20]$. The findings in this study may also help to target adaptation strategies for herders to schedule the movement of their livestock. Herders in Mongolia could adjust their livestock management, including nomadic routes, in advance when autumn precipitation is beyond its usual range. 


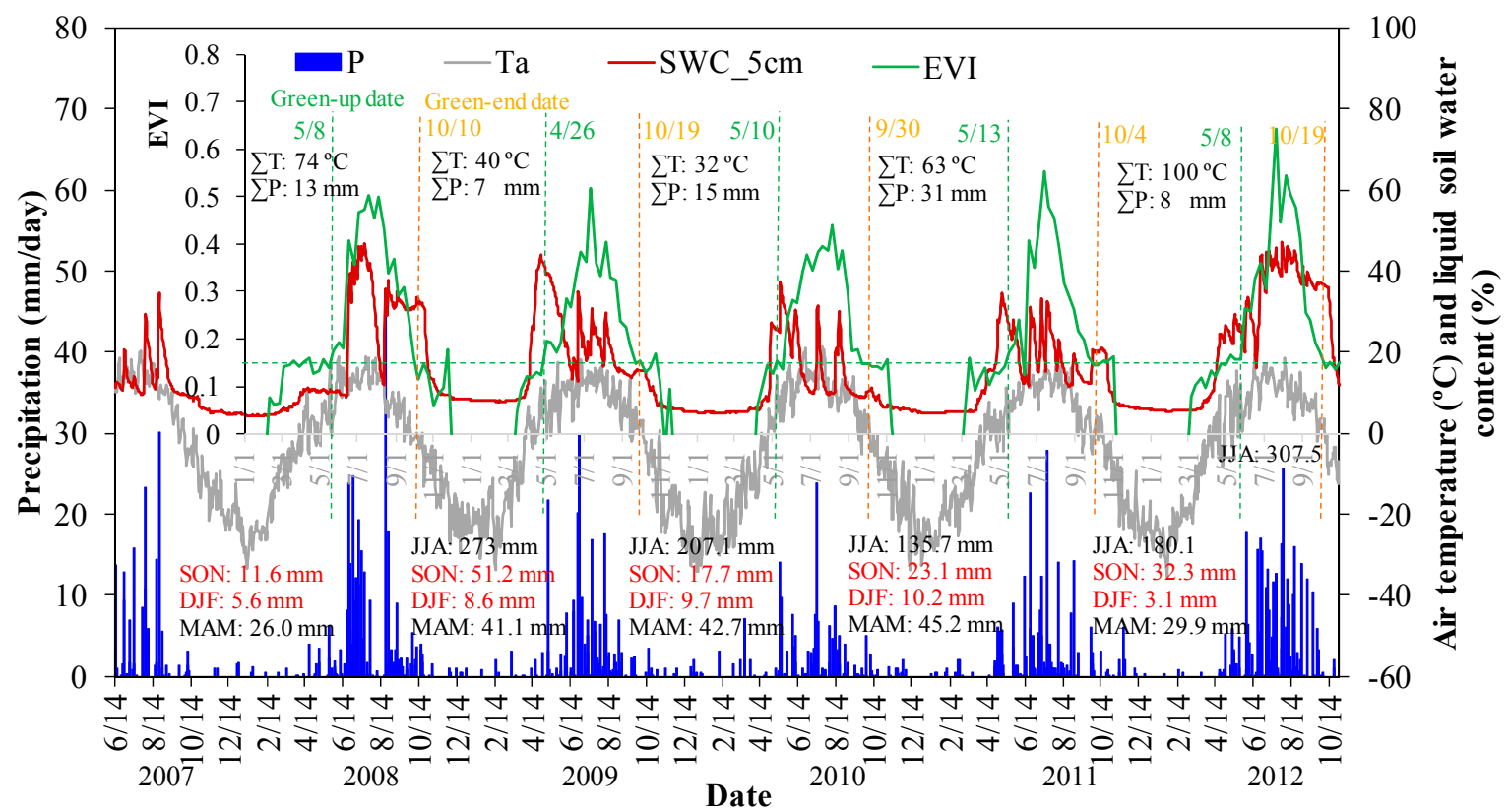

Figure 8. Seasonal patterns of daily rainfall $(\mathrm{P})$, mean air temperature $(\mathrm{Ta})$, volumetric liquid soil water content (SWC) at the $5 \mathrm{~cm}$ depth, and EVI at the Davaat site from 2007 to 2012. $\sum \mathrm{T}$ and $\sum \mathrm{P}$ are cumulative $>0{ }^{\circ} \mathrm{C}$ air temperature and cumulative precipitation before SOS in spring.

\subsection{The Role of Frozen Ground in Regulating SOS}

Only the SOS of steppes over permafrost is significantly negatively correlated with spring air temperature (Figure 5b). The negative correlation for steppe overlying permafrost is consistent with the existing statement that spring temperature dominates SOS over some landscapes with less water stress [11,32]. This result indicates that the remaining water from the previous year stored in frozen soil and the precipitation of winter (snow melt) and early spring could lead to less water stress on the steppe in spring, and then spring air temperature becomes a dominant factor to trigger SOS.

Investigations in this study show that precipitation significantly regulates SOS, and frozen ground plays a vital role in storing precipitation for subsequent grass green-up in Mongolia. An example with detailed ground measurements at the Davaat steppe experiment site could help to further understand the role of frozen ground in storing the precipitation of the previous autumn. As shown in Figure 8, an abrupt concave curve was observed for soil water content at the $5 \mathrm{~cm}$ depth in the late summer of 2008, indicating that most precipitation $(212 \mathrm{~mm})$ in the summer of 2008 evaporated from soil and transpired from grass canopy. Due to relatively low air temperature $\left(<10^{\circ} \mathrm{C}\right)$ and thus low evaporation, the precipitation $(51.2 \mathrm{~mm})$ in the autumn of 2008 led to an increase in soil water content to a stable level of approximately $30 \%$ before frost at the $5 \mathrm{~cm}$ depth. The remaining precipitation in the soil was frozen during the winter. In April 2009, the thawing of this frozen soil water and the $10.2 \mathrm{~mm}$ precipitation that fell during winter contributed to grass growth. Therefore, approximately $70 \mathrm{~mm}$ precipitation from the previous autumn to spring was used for grass green-up and early growth at the Davaat site during the spring of 2009. Approximately $70 \%$ of the total precipitation came from the precipitation in the autumn of 2008. Figure 8 illustrates the importance of both autumn precipitation and frozen ground for grass green-up in the following spring. 


\subsection{Perspectives on Grassland Ecosystem, Permafrost Degradation, and Climate Change in Mongolia}

In this study, statistical results based on remote sensing and climatic data-along with detailed illustrations at an experiment site-suggest that the existence of permafrost is essential for grassland ecosystems in Mongolia, and that the degradation of permafrost caused by climate warming could potentially increase the vulnerability of Mongolian grasslands in the near future. As shown in Figures 4 and $5 \mathrm{~b}$, the spring phenology of the typical steppe is sensitive to interannual climate variability over Mongolian sporadic permafrost and seasonal frozen ground regions. Climate warming might cause permafrost to degrade to sporadic permafrost or seasonal frozen ground. Such degradation might further lead to the degradation of grasslands along the trend from forest steppe to typical steppe, and then to desert steppe. Then, the duration of the grassland growing season would be shortened (Figure 2), and grassland productivity would decrease.

Table 2. Climate, active layer depth (ALD) over permafrost, and phenological dates at three experiment sites. ANN-Ta is the annual mean air temperature, ANN-P is the annual total precipitation, and Stdv is the standard deviation.

\begin{tabular}{ccccccc}
\hline Site & Nalaikh Steppe Site & \multicolumn{2}{c}{ Davaat Steppe Site } & \multicolumn{2}{c}{ Davaat Forest Steppe Site } \\
\hline ANN-Ta $\left({ }^{\circ} \mathrm{C}\right)$ & \multicolumn{2}{c}{-2.8} & \multicolumn{2}{c}{-4.2} & \multicolumn{2}{c}{-5.2} \\
ANN-P (mm/year) & \multicolumn{2}{c}{260} & \multicolumn{2}{c}{270} & \multicolumn{2}{c}{276} \\
ALD (m) & \multicolumn{2}{c}{3.5} & \multicolumn{2}{c}{2.5} & 2.0 & \\
\hline Year & SOS & EOS & SOS & EOS & SOS & EOS \\
\hline 2008 & - & - & $5 / 8$ & $10 / 10$ & $5 / 9$ & $10 / 12$ \\
2009 & $4 / 23$ & $10 / 14$ & $4 / 26$ & $10 / 19$ & $4 / 23$ & $10 / 18$ \\
2010 & $4 / 28$ & $10 / 6$ & $5 / 10$ & $9 / 30$ & $5 / 3$ & $10 / 4$ \\
2011 & $5 / 4$ & $10 / 3$ & $5 / 13$ & $10 / 4$ & $5 / 1$ & $10 / 4$ \\
2012 & $5 / 31$ & $10 / 26$ & $5 / 8$ & $10 / 19$ & $4 / 22$ & $10 / 19$ \\
Mean & $5 / 6$ & $10 / 12$ & $5 / 7$ & $10 / 10$ & $4 / 29$ & $10 / 11$ \\
Stdv (days) & 16.9 & 10.3 & 6.5 & 8.6 & 7.1 & 7.3 \\
\hline
\end{tabular}

An indication of permafrost degradation is an increase in active layer depth (ALD) over permafrost. Three experiment sites with different annual mean air temperatures could represent three scenarios under different warming levels. As shown in Table 2, the results from the Davaat steppe site and the Nalaikh site could be used for forecasting two future scenarios of the Davaat forest steppe site with the increases of $1{ }^{\circ} \mathrm{C}$ and $2.4^{\circ} \mathrm{C}$ in annual mean air temperature, respectively. Then, we can find that the ALD becomes deeper with increasing air temperature, and the SOS tends to be delayed. The standard deviations of SOS and EOS increase from 7.1 to 16.9 days and from 7.3 to 10.3 days, respectively. Results from Table 2 suggest that permafrost degradation, leading to water loss from soil and then water stress on grass growth, could cause the delay of SOS and larger interannual variability of the SOS and EOS.

Recently, Mongolia has experienced a rapid increase in spring air temperature and a moderate decrease in precipitation during autumn, winter, and spring [19]. These trends could make grasslands in Mongolia more vulnerable to climate change. To develop effective adaptation strategies and solutions to relieve or avoid the degradation of permafrost and grasslands, routine observation of grassland ecosystems - including phenology, permafrost, and climate - is needed urgently. Such observation 
would enable better understanding of the relationships among grassland phenology, permafrost, and climate, and would allow the creation of robust phenological models for dry and cold permafrost regions in the near future.

\section{Conclusions}

A detailed investigation into 2001-2009 MODIS phenological data and ground meteorological data was conducted to understand the responses of SOS and EOS to interannual climate variability and the role of frozen ground in regulating SOS over various frozen ground regions across Mongolia. Differing with results reported in previous studies, forest steppe in northern Mongolia has lower air temperature than typical steppe and desert steppe in middle and southern Mongolia, but the SOS and EOS of forest steppe tend to be earlier and later by around 10 days and 5 days, respectively. The SOS and EOS of grasslands demonstrate diverse responses to interannual climate variability in Mongolia, and both of them are less sensitive to it in permafrost regions, suggesting that existing permafrost could moderate interannual shifts of grassland phenological dates due to climate variability. The SOS is dominated by precipitation, especially by the prior autumn precipitation that is stored in frozen soil during the winter, whereas the EOS is dominated by air temperature. Our results could help to counter recent tendencies to over-attribute spring phenological shifts to air temperature, and may help to improve phenological models of grasslands in extremely dry and cold regions. In turn, this may facilitate the development of adaptation strategies for herders to manage their livestock. In future studies, long-term and routine observations of grassland phenology, permafrost, and climate would enable better understanding of the relationships among grassland phenology, permafrost, and climate, and would allow for the development of robust phenological models for dry and cold permafrost regions.

\section{Acknowledgments}

This research was supported by the Environment Research and Technology Development Fund, the Ministry of Environment, Japan. This research was supported by the 100 Talents Program of the Chinese Academy of Sciences.

\section{Author Contributions}

Zhigang Sun and Qinxue Wang conceived and designed the study; Zhigang Sun performed the study; Zhigang Sun analyzed the data; Qingan Xiao, Ochirbat Batkhishig, and Masataka Watanabe contributed materials, analysis tools; Zhigang Sun wrote the paper.

\section{Conflicts of Interest}

The authors declare no conflict of interest.

\section{References}

1. Myneni, R.B.; Keeling, C.D.; Tucker, C.J.; Asrar, G.; Nemani, R.R. Increased plant growth in the northern high latitudes from 1981 to 1991. Nature 1997, 386, 698-702.

2. Korner, C.; Basler, D. Phenology under global warming. Science 2010, 327, 1461-1462. 
3. Schwartz, M.D. Green-wave phenology. Nature 1998, 394, 839-840.

4. Jeong, S.J.; Ho, C.H.; Gim, H.J.; Brown, M.E. Phenology shifts at start vs. end of growing season in temperate vegetation over the northern hemisphere for the period 1982-2008. Glob.Change Biol. 2011, 17, 2385-2399.

5. Menzel, A.; Sparks, T.H.; Estrella, N.; Koch, E.; Aasa, A.; Ahas, R.; Alm-Kubler, K.; Bissolli, P.; Braslavska, O.; Briede, A., et al. European phenological response to climate change matches the warming pattern. Glob.Change Biol. 2006, 12, 1969-1976.

6. Penuelas, J.; Rutishauser, T.; Filella, I. Phenology feedbacks on climate change. Science 2009, 324, 887-888.

7. Lhomme, J.P.; Mougou, R.; Mansour, M. Potential impact of climate change on durum wheat cropping in Tunisia. Clim. Change 2009, 96, 549-564.

8. Ibanez, I.; Primack, R.B.; Miller-Rushing, A.J.; Ellwood, E.; Higuchi, H.; Lee, S.D.; Kobori, H.; Silander, J.A. Forecasting phenology under global warming. Philos. Trans. R. Soc. Lond. B Biol. Sci. 2010, 365, 3247-3260.

9. Yu, H.Y.; Xu, J.C.; Okuto, E.; Luedeling, E. Seasonal response of grasslands to climate change on the Tibetan Plateau. PLoS One 2012, 7, doi:10.1371/journal.pone.0049230.

10. Yu, H.; Luedeling, E.; Xu, J. Winter and spring warming result in delayed spring phenology on the Tibetan Plateau. Proc. Natl. Acad. Sci. U.S.A. 2010, 107, 22151-22156.

11. Shen, M. Spring phenology was not consistently related to winter warming on the Tibetan Plateau. Proc. Natl. Acad. Sci. U.S.A. 2011, 108, E91-E92.

12. White, M.A.; Thornton, P.E.; Running, S.W. A continental phenology model for monitoring vegetation responses to interannual climatic variability. Glob. iogeochem. Cy. 1997, 11, 217-234.

13. Lesica, P.; Kittelson, P.M. Precipitation and temperature are associated with advanced flowering phenology in a semi-arid grassland. J. Arid Environ. 2010, 74, 1013-1017.

14. Shinoda, M.; Ito, S.; Nachinshonhor, G.U.; Erdenetsetseg, D. Phenology of Mongolian grasslands and moisture conditions. J. Meteorol. Soc. Jpn. 2007, 85, 359-367.

15. Cong, N.; Piao, S.L.; Chen, A.P.; Wang, X.H.; Lin, X.; Chen, S.P.; Han, S.J.; Zhou, G.S.; Zhang, X.P. Spring vegetation green-up date in China inferred from SPOT NDVI data: A multiple model analysis. Agr. Forest Meteorol. 2012, 165, 104-113.

16. Yu, F.F.; Price, K.P.; Ellis, J.; Shi, P.J. Response of seasonal vegetation development to climatic variations in Eastern Central Asia. Remote Sens. Environ. 2003, 87, 42-54.

17. Jin, Z.N.; Zhuang, Q.L.; He, J.S.; Luo, T.X.; Shi, Y. Phenology shift from 1989 to 2008 on the Tibetan Plateau: An analysis with a process-based soil physical model and remote sensing data. Clim. hange 2013, 119, 435-449.

18. Liu, H.; Tian, F.; Hu, H.C.; Hu, H.P.; Sivapalan, M. Soil moisture controls on patterns of grass green-up in Inner Mongolia: An index based approach. Hydrol. Earth Syst. Sci. 2013, 17, 805-815.

19. Batima, P. Climate Change Vulnerability and Adaptation in the Livestock Sector of Mongolia-A Final Report Submitted to Assessments of Impacts and Adaptations to Climate Change (AIACC). Available online: http://sedac.ciesin.columbia.edu/aiacc/progress/FinalRept_AIACC_AS06.pdf (accessed on 1 November 2014). 
20. Shen, M.; Tang, Y.; Chen, J.; Zhu, X.; Zheng, Y. Influences of temperature and precipitation before the growing season on spring phenology in grasslands of the central and eastern Qinghai-Tibetan Plateau. Agri. Forest Meteorol. 2011, 151, 1711-1722.

21. Li, R.P.; Zhou, G.S. A temperature-precipitation based leafing model and its application in Northeast China. PLoS One 2012, 7, doi:10.1371/journal.pone.0033192.

22. Sharkhuu, N. Occurrence of frost heaving in the Selenge river basin, Mongolia. Permafrost Periglac. 1999, 10, 187-192.

23. Nelson, F.E.; Outcalt, S.I. A computational method for prediction and regionalization of permafrost. Arctic Alpine Res.1987, 19, 279-288.

24. Wu, T.H.; Wang, Q.C.; Zhao, L.; Batkhishig, O.; Watanabe, M. Observed trends in surface freezing /thawing index over the period 1987-2005 in Mongolia. Cold Reg. Sci. Technol. 2011, 69, $105-111$.

25. Zhang, X.Y.; Friedl, M.A.; Schaaf, C.B. Global vegetation phenology from moderate resolution imaging spectroradiometer (MODIS): Evaluation of global patterns and comparison with in situ measurements. J. Geophys. Res. Biogeo. 2006, 111, doi:10.1029/2006jg000217.

26. Ganguly, S.; Friedl, M.A.; Tan, B.; Zhang, X.Y.; Verma, M. Land surface phenology from MODIS: Characterization of the Collection 5 global land cover dynamics product. Remote Sens. Environ. 2010, 114, 1805-1816.

27. Eriksson, L.; Johansson, E.; Kettaneh-Wold, N.; Trygg, J.; Wikström, C.; Wold, S. Multi- and Megavariate Data Analysis—Part I Basic Principles and Applications, 3rd ed.; MKS Umetrics AB: Umeå, Sweden, 2006.

28. Henebry, G.; Anderson, J.; Losleben, M.; O’Keefe, J.; Shaw, D.; Vanderbilt, K.; Wetherill, K.; Zimmerman, J. A White Paper on Phenology across LTER, 2007. Available online: http://globalmonitoring.sdstate.edu/LTER-phenology/LTER_Phenology_White_Paper.pdf (accessed on 1 November 2014).

29. Xiao, W.W.; Sun, Z.G.; Wang, Q.X.; Yang, Y.H. Evaluating MODIS phenology product for rotating croplands through ground observations. J. Appl. Remote Sens 2013, 7, doi:10.1117/1.jrs.7.073562.

30. Zhang, Y.S.; Munkhtsetseg, E.; Kadota, T.; Ohata, T. An observational study of ecohydrology of a sparse grassland at the edge of the Eurasian cryosphere in Mongolia. J. Geophys. Res. Atmos. 2005, 110, doi:10.1029/2004jd005474.

31. Shinoda, M.; Nandintsetseg, B. Soil moisture and vegetation memories in a cold, arid climate. Glob. Planet. Change 2011, 79, 110-117.

32. Zeng, H.Q.; Jia, G.S.; Epstein, H. Recent changes in phenology over the northern high latitudes detected from multi-satellite data. Environ. Res. Lett. 2011, 6, doi:10.1088/1748-9326/6/4/045508.

(C) 2014 by the authors; licensee MDPI, Basel, Switzerland. This article is an open access article distributed under the terms and conditions of the Creative Commons Attribution license (http://creativecommons.org/licenses/by/4.0/). 